\title{
Data Mining Technology and Techniques in Medical Science Field Application
}

\author{
Namratha Gonuguntla, Swarnalatha $\mathbf{P}$
}

\begin{abstract}
The electronic and the written records both played an equally significant part in the daily lives of the health department staffs. However, after the globalised version of change in the healthcare department, it has been recorded by the researcher in his examination a portion of the fundamental focuses that demonstrate the genuine advantage of the information and the dangers. Consequently in this report, the analysts will show unmistakably the Data mining procedure and its different focuses. The primary focal point of the investigation is needy upon the Nursing work, and in this manner various health care centres and the nurses will be taken under consideration. The report additionally examines about the data mining subject's experience and how it rose in the therapeutic science field of capacity. The information that are dealt with in the framework has changed into a making care each. It has been noticed that information mining is considered to all computer-based information stockpiling and recovering method. The approach of the digital form of data gathering will also be explained and along with it will also showcase some critical points that are co-related with the findings and analysis. In the end, the researcher will provide its own recommendation for the betterment of the nursing in the medical science field of capacity.
\end{abstract}

Keywords : Administration, analytics, diagnosis, HealthCare and nursing.

\section{INTRODUCTION}

The globalised technological world is collecting various types of data and accumulating it to make the information more vivid so that during any form of crisis or emergency the information can easily be found. The data that are stored in the system has become a growing awareness every human being, and therefore the new generation of IT management and innovation has created a method of data mining. The data mining process involves the pattern of discovery and extraction of new vivid data. According to this report the researcher has chosen Nursing as the specific core of research in the data mining of medical field, and all the research are based upon the Australian medical institutions. Medical and the healthcare institutions carry out their work managing the overall data of their patients and the medical procedures by the nurses and the data are collectively stored in the computers that are connected by a local area network system. In this report, the researchers have clearly mentioned about the nursing job, and the data mining process is used by the nurses as well as the health care institutions.

Revised Manuscript Received on December 16, 2019.

* Correspondence Author, ${ }^{\mathbf{1}}$ First Author

Gonuguntla Namratha ${ }^{1}$, Computer Science and Engineering,Vellore Institute of Technology,Vellore, India, Email:

gonuguntlanamratha@gmail.com

Swarnalatha $\mathbf{P}^{*}$, Computer Science and Engineering,Vellore Institute of Technology, Vellore, India, Email: hgswarna@gmail.com
This report will also reflect upon the various approaches and the findings and analysis of the data mining that includes the issues and opportunities, utilisation of the data mining, benefits, and shared risks. The researcher will also contribute its own recommendation in order to make the process of data mining easy and flexible.

\section{PRIMARY DATA ON MEDICAL FIELD}

Healthcare institutions are mostly engaged with the diagnosis and the treatment of the patients. In order to make the work easier for the officials and the executives of the hospital, data mining is used. The hospitals and the nurses are responsible for the development of the healthcare situation of the civilians, and all the records cannot be stored in the dataset of the organisation in a single system basis. Therefore data mining helps every department of the health care institution to collect the data and make it available in the educational cloud technology. The health care institution mostly focuses upon prevention of the disease and any other physical or mental injury, and in this process, the nurses are given the responsibility of taking care of the patients and its development to be recorded in the hospital portal records [1]. The healthcare organisation or the industries are growing in a rapid force, and the evolutions of its management are also getting modified in a daily manner. The data that are received by the health care industries carries an abundant amount of data in terms of digital medical records, administrative records and other findings of the medical process such rare medicines or procedures of treatment. These health care institutions are mostly engaged with the development of the people, and this lacks behind the data preservation of the medical institutions. In the research, various Australian institutions are analyzed, and the data have been received that nurses are mostly trained to operate in the field of nursing work and medicine preservation [2]. The preservation of data of the patients the medical records are not well defined in the record system of the hospitals. [Referred to Appendix 2]

The health care institutions in Australia consists of 3 types of data recording; analysis of the patients, analysis of the medical procedures and the data recording techniques. The nurses, however, operate the daily job of taking care of the patients in the daily but the training for the system management and the digital process work are almost left behind. According to the analysis the nurses who have the workforce before 2012 they are all lagging behind with the proper and efficient knowledge about the process and the working of the institution. The nurses who 
have joined the hospitals or the care institutions after 2014 they are all given the training of digital devices and training based upon the IT is considered to be one of the mandatory parts of the working in the medical environment. Although the digitisation process has grown to its limits and most of the institution are now registering and authorising all the nurses for the IT-based training programme so that the data processing work could be faster [3]. Data mining and other processing work were also given the order to complete all the given processed type of work on the basis of HWA, i.e. Health Workforce of Australia. According to the study the researcher has also stated that the digitisation process and the data mining in the healthcare institution had grown from $12 \%$ in 2012 to $68 \%$ in 2018 . Therefore in a span of 6 years not the health care institutions but also the nurses are well guided in the process of patients data, medical requirements and other medical pieces of information. [Referred to Appendix 1]

\section{SYSTEM OF APPROACH}

The strategic work that has been undertaken by the health care institution with a simple method of the data mining technique. This strategic work is totally based written with the primary aim upon the academic research of Australian nurses. The nursing work and the health care institution involvement in the data keeping and processing the records are totally dependent upon the three types of approach [4]. The implementation of the three types of system indicates the three keys to create a portal and driving into the workforce of the real world. The analytics and initiatives are also recorded in the data processing unit. However, the data process system consists of three types of approach system that explained in the following points:

\section{-Analytics system}

According to this system, it includes the technological and ethical form of system analytics. The technological area shows the part of the improvement in the analysis. However, the analysis is procured during the working process by the nurses or any other executives. The data are standardised and the useful measurements regarding the finance of the patient, previous clinical data and the satisfaction that is achieved by the patient that is presented by the executives and the aggregated data [5]. The data that are realised by the data input method is done into the EDW, and it creates a foundation in the system for the medical process work. This system of approach is relatively regarded as the Analytics System.

\section{- Best Practice System}

According to this system of work the practice system totally depends upon the standardised knowledge of the health care professionals and the medical information, outputs are effectively practised by the practice system approach. The systematic collection of the evidence or the patient's practice methods are clearly explained by the analytical method. According to the researcher, this approach provides the analysation of the practice system of the nurses in the input of the data and makes it significant every year. The best system practices have a basic type of approach that regards to the overall work of the clinical practice or its sessions [6]. The data mining creates a portal for this system of work, and therefore the medical evidence is likely to be available quickly.

\section{-Adoption System}

According to this system of approach, the system of the medical procedures and the change in the structural management are effectively changed in order to create a sub-portal of work. The structural changes in the management process are done by the executives and are processed down to the nurses and the medical helping hands. It helps to construct the organisational change and adapt the best practice for medical work and the best IT changes whether its web portal or the cloud system of computing. The adaptation system helps to create a new approach in the medical environment in Australia.

The Data mining process is considered to be one of the major players in the exercise of all the system of approach. It is considered that if the approach does not implement the work, then the academic review of the data becomes in a long featured structured [7]. On the other hand, if the approach is maintained the clinical practice as well the nursing job remains to entitled as the work based upon the health care practice.

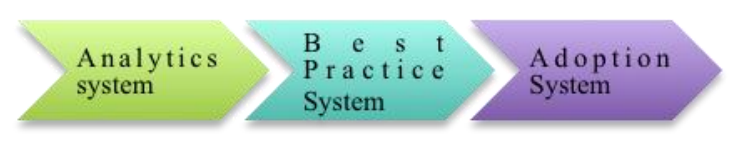

Fig 1 - Three types of approach system (Source: Created by the Author)

\section{FINDINGS AND ANALYSIS}

\subsection{Issues and Opportunities}

The nursing knowledge has been embedded upon the nurses after their training programme and the knowledge about medicine and also about the digital process of the work. However, expertise the knowledge of nursing to the workers creates a significant key to the quality of the patient care being high and managing the cost-effectiveness of the healthcare institution. In the digitalised world everything and every human subject are dependent upon working with the machines [8]. These problems remain to unresolved, and a technique used by most of the most that mixing the using the technology in the daily basis of work is done to make the health care centres an effective cost generative place. However, in the due process of work, the clinical work has two opportunities that are based upon the knowledge of the 
Nurses through values and knowledge; another is the data mining process by which the nursing knowledge is achieved.

\section{-Values known by the nurses}

The nursing work in Australia totally depends on the overall structure of the health care department. The problems that are faced during this work are explicitly explained by the researcher as a twofold basis format. The first problem that is faced; the data that are stored may not have collective information on the basis of the work. The data that are collected on a daily basis are recorded in the value chart of the medical procedure. However, most of the works are explicitly based on oral and interactive sessions. These sessions are often conveyed in the digital data in a small format, and this small data creates a problem when procuring the real data. It has been noted by the researcher that most of the nursing data are collected in the paper format and it becomes difficult while interpreting the data into the computer [9]. The researcher has also regarded that most of the computer-based system has a low amount of storage and data input exceeds the limitation of the storage unit.

\section{-Knowledge discovery based upon Data mining}

KDD or the Knowledge discovery Database helps to create another opportunity for extracting the information and the potential possibilities that may be related to the medical procedures in Australia. The KDD has been identified as one of the primary sources of data mining technique, and it follows the rule of computer-based resources and the data cloud resources. This data mining helps the nurses to get a better knowledge about the statistical output and the interchangeable variables such the finance or the clinical data output of the medical tests. The nursing work can use in data mining as it helps to build knowledge about the subject material and the medical decisions that are made by the experts or the doctors.

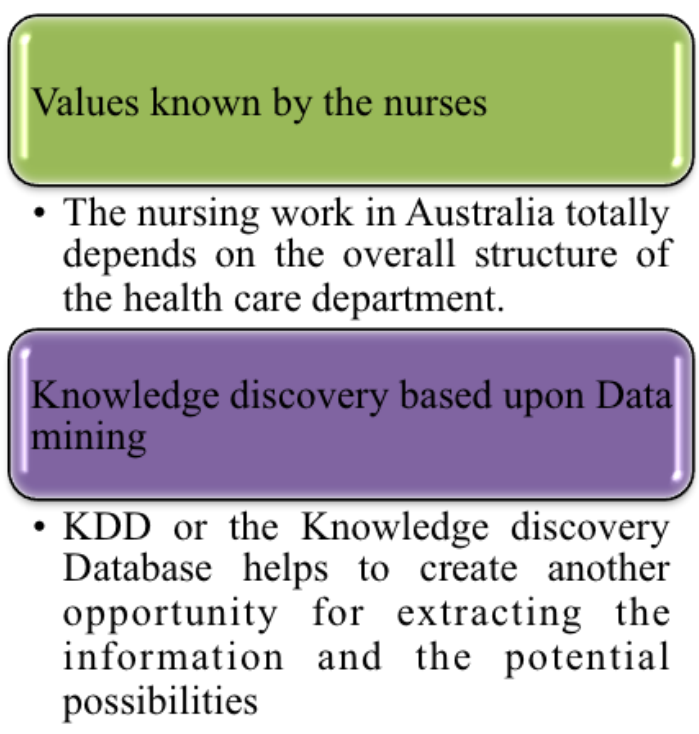

Fig 2: - Issues and Opportunities for Data mining (Source: Created by the Author)

\subsection{Utilisation of Data Mining}

Electronic or digital health records have been quite common among health care centres in the world. In Australia the method of data records that restored are mostly on the basis of the paper framework of the company but when the globalised world of patients care, and the medical procedures evolved Australian health data processing techniques created a little loophole in the structure of the computerised function. In order to make Data mining more efficient the network background of the health care institution are cleared, and due to this, the cost of framing the work has been quite efficient [10]. Health care services have decided that after the massive change in the global medical procedure today health care centres are seeking benefits through data mining that helps to get the data of the patient. It also helps the healthcare centres from any kind of fraudulent services in the world and the helps to create a better check upon the activities of the people. The utilisation of Data mining in the Australian health care centres and their types are explicitly explained in the following points:

\section{-Measuring the Effectiveness of the patients}

Data that are involved with the application or the software are used for the data mining technique are compared and contrasted with various types of data that are presently available to the market. The effectiveness of the patients is measured through the buying of the medicines and consuming it. Nurses perform their job in terms of keeping a check upon the times of the consumption of the medicine.

\section{-Detection of Fraudulent and Abuse}

In this second point of the utilisation of the Data mining, the researcher states that all the valid data regarded the health measurement and the medical claims that show an unusual form of the pattern in the clinics and the other labs [11]. This data mining determines whether the patient is using a fraud identity in order to buy more drugs or abusing medicines. The nurses are given the responsibility for the check of balance.

This technology has been regarded as the most efficient mode of data mining and this data mining method has almost created a broad vision of knowledge, and various medical departments have recovered 1.6 million dollars.

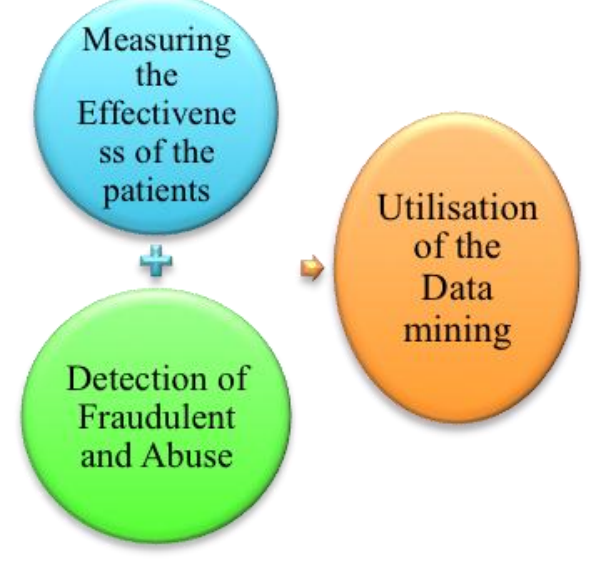

Fig 3 - Utilisation of the Data mining (Source: Created by the Author)

\subsection{Data mining overview}

According to the research the Australian Government and the HealthCare Service department the size of the data is growing at a very rapid pace, 
and soon it will be overviewed upon the informative techniques. In a world of growing complex informative styled information in the medical field, the data stored in the cloud storage that gives access to the vast number of the audience but the permission is only given to those number of people who actually the working in the medical world [13]. The Data mining technique also uses the computer-based integrated system of the identification and financial, statistical procurement. The data mining helps the audience to provide them with a broad scope of knowledge and provide each and every patient with a healthy lifestyle. However, it is the duty of the nurses to keep a check upon the patients and to create the input data in the CBIS of the health information system. Some of the basic overviews of Data mining are as follows:

\section{-Discipline in Data mining}

Data mining involves discipline in the process of learning through machines and the integration of the artificial technique of data input and statistics. The data mining also keeps a check on the future probability of the patient's health effect.

\section{- Model of Data Mining}

According to the research it has been recorded by the researcher that there are two types of models in the Data Mining Technique. The two types of models are as follows; Predictive Model and the Descriptive Model.

\section{- The task of Data Mining}

The explanation of the data mining is already given, but the task that is performed by Nurses with the use of Data mining technique involves clustering, associative rules, correlation analysis, and categorisation. These are all the underliners of the Model of Data Mining.

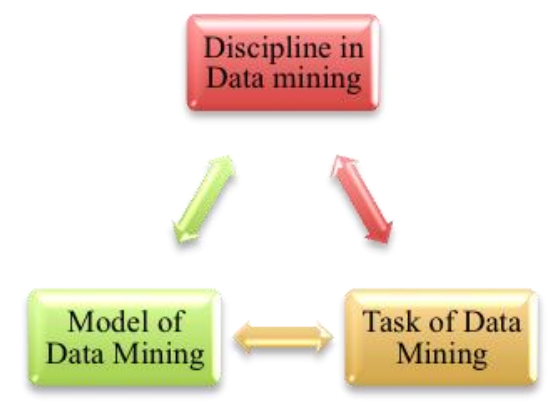

Fig 4 - Data mining overview (Source: Created by the Author)

\subsection{Benefits of Data mining and model}

Mining related to data had been effective in the field of medicine. Here the field that was chosen was nursing. The purpose of the mining of the data was uncovering the pattern from vast and numerous numbers of information and constructed the models which would be predictive. The practice of such mining had provided enormous help in the nursing field and also in other different types of medical fields by detecting fraudulent, scoring of the credit and maintaining schedules of different programs related to the health care. Mining of data had been proven to be beneficial in improvising in the methods of taking care of the patients, reducing the cost of the healthcare and many more [14]. Apart from other methods which favour the providers of the healthcare or companies related to insurance, mining of data benefits everyone in the organisation of healthcare and also those who acted as insurers on behalf of the patients. The database of the mining of data contains the information related to all the patients and also outlining the factors like the risks of the health care problem of the patient and the identifying the treatment which would go with the condition of the patient [15].

According to the condition of the patient, they would adhere to better affordable treatment, better service of healthcare. A sheet would be generated for the nurses who would take care of the patients according to the sheet that was provided to them. The sheet would contain all the necessary things the nurses have to perform on a regular basis for the patients [16]. The mining of data identifies the diseases related to chronic according to which the construction of the intervention was done thus reducing the numerous types of claims and admissions of the hospital. The tools of mining compare adverse effects, treatments, causes, and symptoms and coming up with the best treatment on the care standards and best practices related to clinical which would be provided by the providers of healthcare. Mining of data had helped the insurers in detecting the fraudulent related to the insurance of medical. The tools of mining had also helped in helping the providers with better decisions regarding the condition of the patient and how could it be improved further [17]. It had also taken care of the present and future needs in improvising the treatment methods of the patients, needs of the patients along with which the preference of the patients was kept in mind thus helping in the process of the treatment. [Referred to Appendix 3]

\subsection{Using of Analytics in Track fee service and Contracts of Value-Based Player}

This section would address the facts related to the working of the mining of data in a more detailed manner. Mining helps in leading a smooth and better transition of fees for services to the model of reimbursement based on value. It had been observed that transition based on the model of reimbursement based on values was the form of representing the future related to healthcare. Apart from the mentioned model, the system of healthcare has to go through several models related to healthcare. The system of healthcare had to work with all the members of the healthcare for navigating the transition related to the fees. The fees were generally based on the treatment along with the medication provided to the patients by the nurses [18]. As it had been already mentioned that a sheet was provided for the nurses which contain all the steps along with the necessities the nurse have to abide by to treat the patients, providing them with better quality of care and giving them medication on the proposed time. Apart from fulfilling all the necessity tasks regarding the patient, the practice of nursing according to the mining of data also involves creating a report regarding the condition of the patient, the activities that were carried out on the patient to improve their condition, the meals that were provided to them, writing down the time of the medication provided to them and many more. 
According to the report provided by the nurse further actions were taken to modify the list to ensure a tad bit more adequate and accurate treatment to the patient [19]. The information about the modification also stored in the database of the mining of data for further use. Mining of data in the field of nursing also helped the organisation of healthcare by dividing the work of each nurse according to the conditions of the patients. The nurses have to follow each of the tasks provided in the sheet and also have to take care of the preferences and needs of the patients [23]. The sheet that was generated with the help of the mining of data helps the nurses in carrying out their job effectively. However, the organisations have to list out the interventions regarding the nurses before assigning them with the task sheet. The intervention basically adheres to listing out the needs, preference of the patients and jotting down the conditions of the patients and then outlining the goals of nursing.

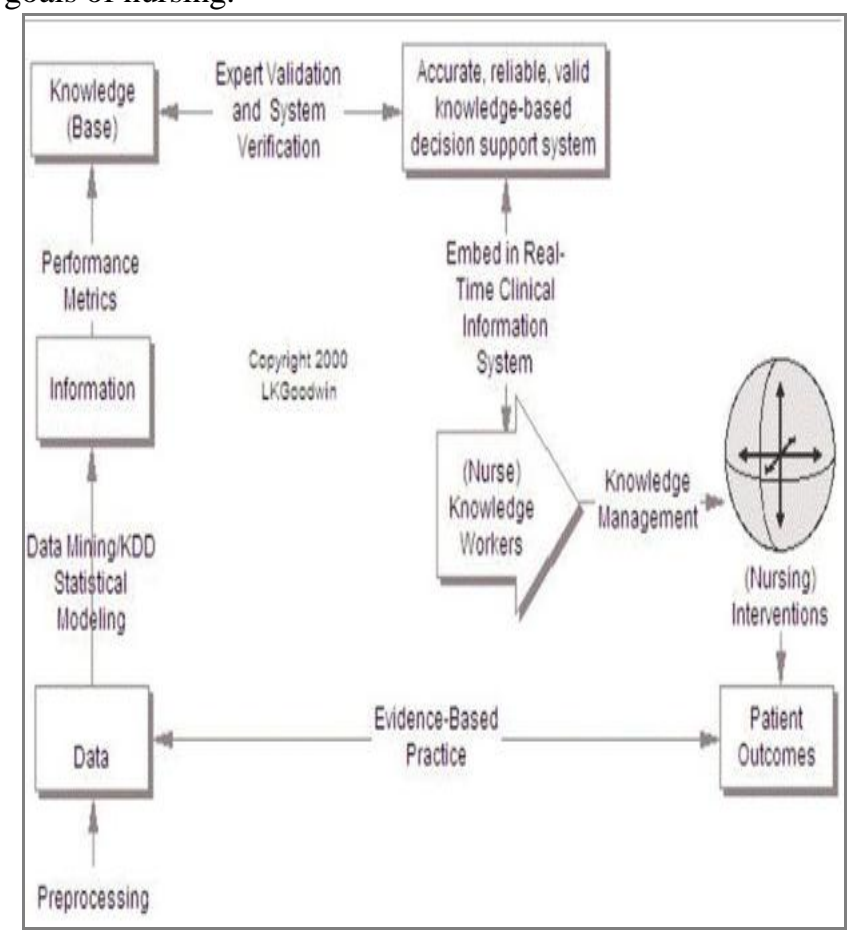

Fig 5 -Data mining methods for nursing knowledge development

(Source:https://www.sciencedirect.com/science/article/pii/S1 532046403001011)

\subsection{Shared Risk Contracts}

Mining of data had many benefits, but along with that, there were some risks which it adheres. The organisation of healthcare caters to different types of patients who after recovery leave the hospital. Deletions of those data were not done in the mining of data which serves as one of the pitfalls of mining of data thus initiating the risks [20]. As mining of data supports the making of the decision on regular activities which results in overvaluation that is the information provided by the mining of data would never create any distinguishable difference in the organisation. It also had been observed that the data produced with the help of mining are huge and structural data which were hard to work on by the managers, poor quality of data deviates the managers from making a concrete and accurate decision and makes their decision a wrong one as they were based on the information and data provided by the mining of data. Sometimes the mining of data provides patterns which could be meaningless without any correlation [21]. The significant risk regarding the mining of data was when the previous data along with information were not deleted thus filling up the memory of the database which means taking up the places which could have been used on inserting new data of the existing patients.

Allocating such a substantial amount of data leads to taking up all the memory of the database and creating the problem for the organisation that faces problem in distinguishing and finding data which are needed to be spotted for the use of the organisation. Decisions which were made in the field of nursing with the help of the mining of data could not be accurate all the time thus making the organisation in taking a wrong decision which could affect the organisation very badly in future [22]. The sheet of tasks that were provided by the organisation to the nurses based on the information on the mining of data sometimes might put the organisation in a risky position when there was no correlation with the condition of the patient with the task that was given in the list to carry out [24]. Overall it could adhere that the system of mining of data could be modified more to eradicate the risks. There was no doubt that the mining of data helps the organisation of healthcare in a significant way. Therefore, modifications in a few parts could help the model of predictive to be more predictive and accurate for making the decision. [Referred to Appendix 4]

\section{RECOMMENDATION}

The researcher has provided some of his recommendation that is explained in the following points:

\section{- Privacy control}

Data mining by the nurses and other healthcare members reflect that nursing job is to take care of the patients and prevent the privacy of their identification. The privacy control should contain the stricter amount of checking.

\section{- New Technology should be integrated}

In order to have better input of data new innovative technology and the upgradation of technology must be added.

\section{- Nurses should be well trained}

The nurses must be trained in the IT-based works to overcome a lack of knowledge about data mining.

\section{CONCLUSION}

According to this report Data mining of the medical field has explained various techniques and the causes of data mining. The data mining creates a great potentiality in the department of healthcare, and it also helps enable the system analytics for identification of the disease or medication of the patients. The focus of the report has been based upon the nursing job, and the researcher has mentioned the background of the medical field and the introduction of the data in the nursing job. In the report, the approaches system and the Findings and analysis has also been mentioned. The researcher has concluded the report with its own recommendation.

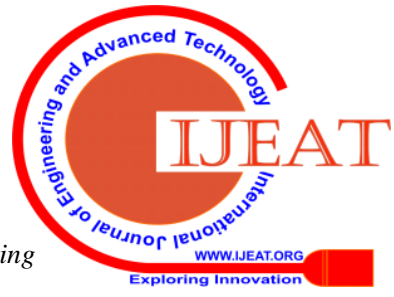




\section{APPENDICES}

Appendix 1

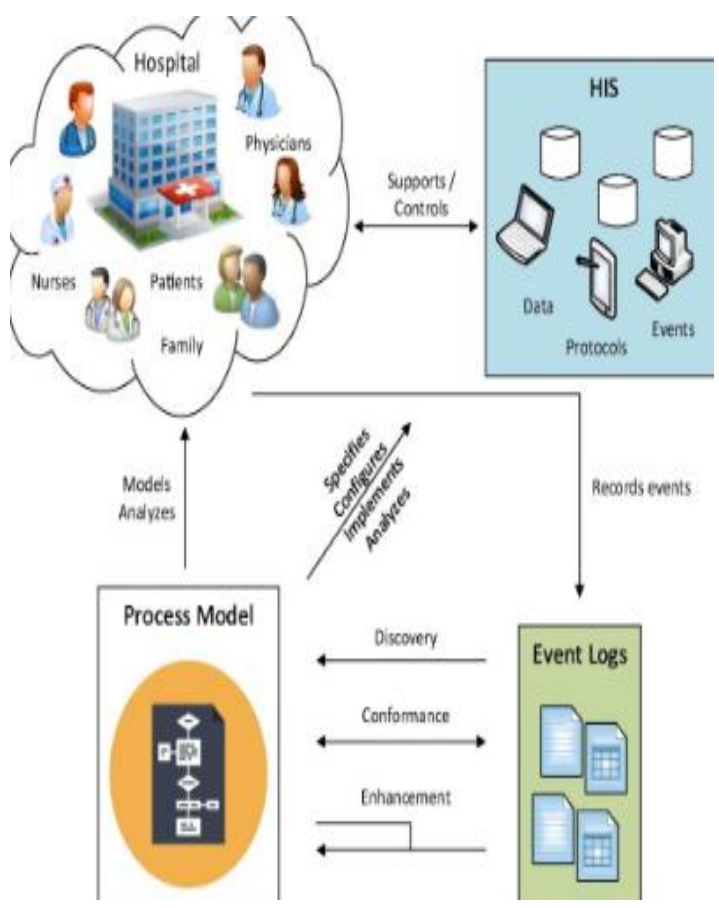

(Source:

https://www.sciencedirect.com/science/article/pii/S153 2046416300296)

Appendix 2

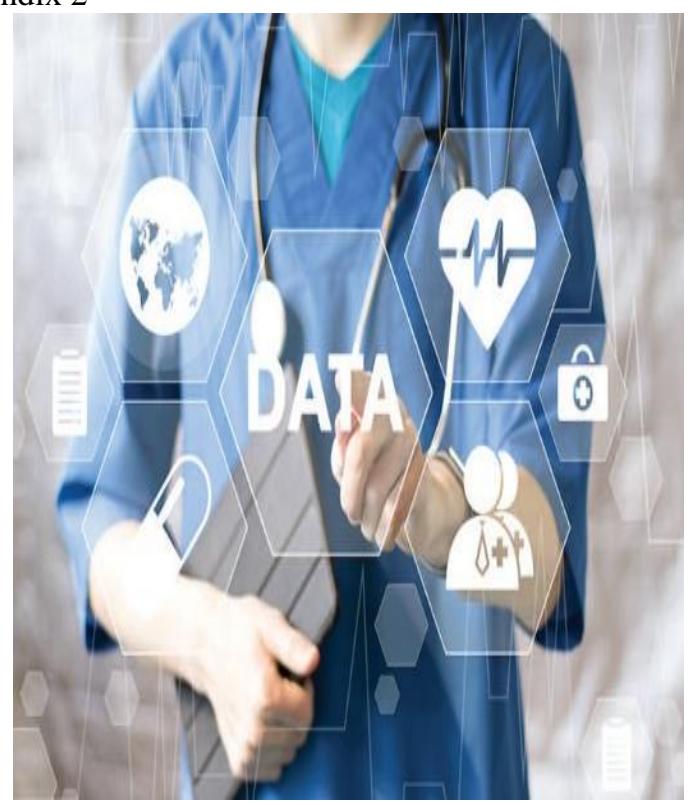

(Source:

https://www.americannursetoday.com/big-data-nursing/)
Appendix 3

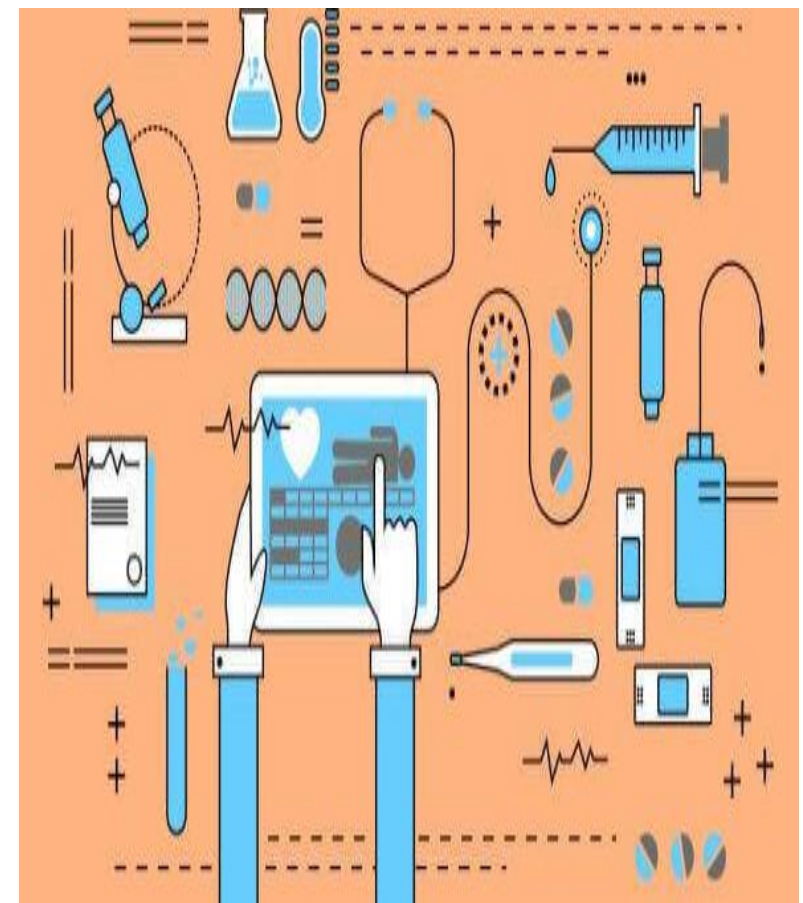

(Source:

https://www.datapine.com/blog/big-data-examples-in-h ealthcare/)

Appendix 4

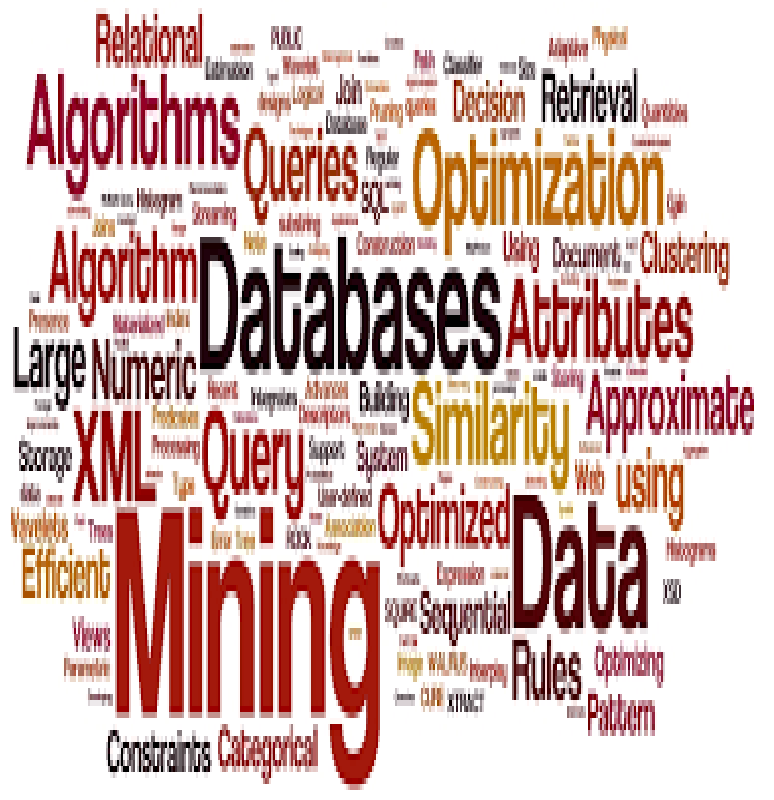

(Source:

https://goldbaniga.wordpress.com/category/nursing-informat ics-administrative-application/)

\section{ACKNOWLEDGMENT}

I would like to take be greatful to my mentor Prof. Swarnalatha $\mathrm{P}$ for guiding me and my college VIT University, Vellore for giving me this opportunity.

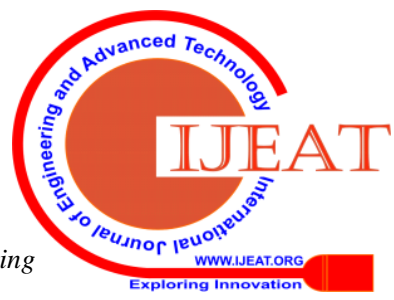




\section{REFERENCES}

T. P.N, Introduction to data mining. Pearson Education India, 2018

1. W. I.H, F. E., H. M.A and P. C.J, Data Mining: Practical machine learning tools and techniques. United States: Morgan Kaufmann, 2016.

2. D. Raju, X. Su, P. Patrician, L. Loan and M. McCarthy, "Exploring factors associated with pressure ulcers: A data mining approach", International Journal of Nursing Studies, vol. 52, no. 1, pp. 102-111, 2015. Available: 10.1016/j.ijnurstu.2014.08.002.

3. A. Khokhar, M. Lodhi, Y. Yao, R. Ansari, G. Keenan and D. Wilkie, "Framework for Mining and Analysis of Standardized Nursing Care Plan Data", Western Journal of Nursing Research, vol. 39, no. 1, pp. 20-41, 2016. Available: 10.1177/0193945916672828.

4. T. M and P. L, "Big Data and nursing: implications for the future", Stud Health Technol Inform, vol. 232, no. 2, pp. 165-171, 2017. [Accessed 27 March 2019].

5. J. Samuels, R. McGrath, S. Fetzer, P. Mittal and D. Bourgoine, "Using the Electronic Health Record in Nursing Research", Western Journal of Nursing Research, vol. 37, no. 10, pp. 1284-1294, 2015. Available: $10.1177 / 0193945915576778$

6. S. Henly et al., "Integrating emerging areas of nursing science into PhD programs", Nursing Outlook, vol. 63, no. 4, pp. 408-416, 2015. Available: 10.1016/j.outlook.2015.04.010.

7. G. Gao et al., "A strengths-based data capture model: mining data-driven and person-centred health assets", JAMIA Open, vol. 1, no. 1, pp. 11-14, 2018. Available: 10.1093/jamiaopen/ooy015.

8. S. Brown, S. White and N. Power, "Introductory anatomy and physiology in an undergraduate nursing curriculum", Advances in Physiology Education, vol. 41, no. 1, pp. 56-61, 2017. Available: 10.1152/advan.00112.2016.

9. A. Leary, B. Tomai, A. Swift, A. Woodward and K. Hurst, "Nurse staffing levels and outcomes - mining the UK national data sets for insight", International Journal of Health Care Quality Assurance, vol. 30, no. 3, pp. 235-247, 2017. Available: 10.1108/ijhcqa-08-2016-0118.

10. M. Kazemi, S. Hajian and N. Kiani, "Quality Control and Classification of Steel Plates Faults Using Data Mining", Applied Mathematics \& Information Sciences Letters, vol. 6, no. 2, pp. 59-67, 2018. Available: 10.18576/amisl/060202.

11. S. Henly et al., "Emerging areas of science: Recommendations for Nursing Science Education from the Council for the Advancement of Nursing Science Idea Festival", Nursing Outlook, vol. 63, no. 4, pp. 398-407, 2015. Available: 10.1016/j.outlook.2015.04.007.

12. H. Lach, K. Buckwalter and L. Aaronson, "Midwest Nursing Research Society News", Western Journal of Nursing Research, vol. 37, no. 7, pp. 1005-1008, 2015. Available: 10.1177/0193945915586899.

13. J. Xu, Y. Zhang, P. Zhang, A. Mahmood, Y. Li and S. Khatoon, "Data Mining on ICU Mortality Prediction Using Early Temporal Data: A Survey", International Journal of Information Technology \& Decision Making, vol. 16, no. 01, pp. 117-159, 2017. Available: 10.1142/s0219622016300020.

14. N. N. and R. Kulkarni, "Appraisal Management System using Data mining Classification Technique", International Journal of Computer Applications, vol. 135, no. 12, pp. 45-50, 2016. Available: 10.5120/ijca2016908596.

15. L. McKenna, E. Halcomb, R. Lane, N. Zwar and G. Russell, "An investigation of barriers and enablers to advanced nursing roles in Australian general practice", Collegian, vol. 22, no. 2, pp. 183-189, 2015. Available: 10.1016/j.colegn.2015.02.003

16. S. Inoue, N. Ueda, Y. Nohara and N. Nakashima, "Recognizing and Understanding Nursing Activities for a Whole Day with a Big Dataset", Journal of Information Processing, vol. 24, no. 6, pp. 853-866, 2016. Available: 10.2197/ipsjjip.24.853.

17. S. Henly et al., "Emerging areas of nursing science and $\mathrm{PhD}$ education for the 21st century: Response to commentaries", Nursing Outlook, vol. 63, no. 4, pp. 439-445, 2015. Available: 10.1016/j.outlook.2015.05.003.

18. D. Mining and C. Us, "Data Mining | The Data Mining Group, Melbourne, Australia", The Data Mining Group, 2019. [Online]. Available: http://www.data-mining.com.au/. [Accessed: 27- Mar2019].

19. ["Nursing In Australia - in Three Steps", Health Times, 2019. [Online]. Available:

https://healthtimes.com.au/hub/nursing-careers/6/guidance/nc1/nursi ng-in-australia-in-three-steps/569/. [Accessed: 27- Mar- 2019].
20. "Data Mining", Data Analysis Australia, 2019. [Online]. Available: https://www.daa.com.au/articles/analytical-ideas/data-mining/. [Accessed: 27- Mar- 2019].

21. sciencedirect.com, 2015. [Online]. Available: https://www.sciencedirect.com/science/article/pii/S18770509150360 66. [Accessed: 27- Mar- 2019]

22. nursingnow.org, 2018. [Online]. Available: https://www.nursingnow.org/transforming-nursing-in-australia/. [Accessed: 27- Mar- 2019].

23. J. Stephenson, M. Ford, M. Ford and J. Stephenson, "What is in store for the future of the nursing industry in Australia?", Nursing Times, 2019. [Online]. Available: https://www.nursingtimes.net/news/workforce/whats-in-store-for-thefuture-of-the-nursing-industry-in-australia/7027855.article. [Accessed: 27- Mar- 2019].

\section{AUTHORS PROFILE}

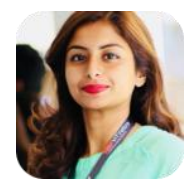

Gonuguntla Namratha, is a student who is very much interested in exploring and implementing emerging trends in IT sector. She is currently working as cyber security engineer in Cognizant Technology solutions for a Health Insurance company called Horizon located in New Jersey. She has attended one international, "The 2nd World Summit on Advances in Science", Engineering and Technology at Indiana University-Purdue University, Indianapolis, USA. She is interested to work in cyber security, block chain, Deep learning and Data Mining domains along with other domains in IT. She also was a part of many organizations such as TEDxVITVellore, IEEE industry Application Society.

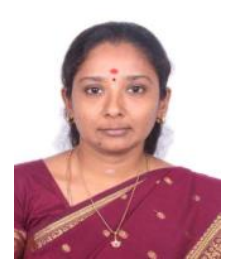

Dr. Swarnalatha $\mathbf{P}$ completed her M.Tech. Degree in 2006 with first rank in Computer Science and Engineering at VIT University, Vellore. She pursued her doctoral programme in the same institution and obtained her Ph.D. Starting as a Teaching Assistant in 2001. She had a deep involvement in teaching courses and was awarded the best uploading of courses between 2006 to 2009 and had a deep involvement in Image Processing, Artificial Intelligence and Software Engineering and was awarded for the Research Award at VIT University, Vellore. So far she has received 5 awards. Her work on Image Processing for medical and satellite images bought her a funded project on "Development of approaches for geometric, radiometric and atmospheric correction of remote sensing data projects for multi-date data analysis" by Space Application Centre-Ahmedabad at VIT University, Vellore and consultancy work for $\mathrm{CMC}$, Vellore. She was invited by many conferences and for guest lectures for Image Processing, Artificial Intelligence and Software Engineering. She immersed herself in conducting research in chosen area of specialization, guiding $\mathrm{Ph} . \mathrm{D}$. projects and M.Tech. students and teaching at undergraduate and post graduate level. Over 70 B.Tech students, 30M.Tech students, and 100 MS students stand testimony for her productivity in Image Processing, Artificial Intelligence and Software Engineering research. She published more than 75+ papers in national and international journals and conferences. She is a Member of many Professional Societies such as Life Member of Computer society of India (CSI) Professional Member of Association of Computing Machinery (ACM), Senior Member of IEEE and Member of ACEEE. 